\section{INFORMATION ABOUT THE AUTHOR}

SHANDRUK Svitlana Ivanivna - Doctor of Pedagogical Sciences, Professor, Head of the Department of Linguodidactics and Foreign Languages of Centralukrainian Volodymyr
Vynnychenko State Pedagogical University.

Circle of scientific interests: professional education, comparative pedagogy.

Стаття надійшла до редакиії 03.11.2019 p.

\title{
УДК 004.42
}

DOI:10.36550/2415-7988-2019-1-185-77-80

БОЛІЛИЙ Василь Олександрович кандидат фізико-математичних наук, доцент, доцент кафедри інформатики та IT Центральноукраїнського державного педагогічного університету імені Володимира Винниченка ORCID: https://orcid.org/ 0000-0002-1923-1058 e-mail: basilb@kspu.kr.ua

\section{АВТОМАТИЗОВАНА СИСТЕМИ ОБЛІКУ «АХІМ»}

\begin{abstract}
Постановка та обгрунтування актуальності проблеми. $\mathrm{y}$ наш час автоматизація зачіпає всі великі сфери бізнесу. Сучасні комп'ютерні програми допомагають виконувати більшу частину рутинної роботи, ефективно керуючи основними i допоміжними процесами. Особливо необхідним є застосування систем автоматизації на підприємствах торгівлі, при цьому вони однаково ефективні як для великих торгових мереж, так і для малих магазинів. Якщо для великої компанії автоматизація торгових процесів розглядається вже як єдина правильна стратегія розвитку бізнесу, то для малої компанії - це спосіб підвищення ефективності роботи, зміцнення ринкових позицій [1].
\end{abstract}

Аналіз останніх досліджень i публікацій. Програми обліку набули популярності та необхідності у використанні. Проаналізувавши ринок програм обліку («1C: Роздріб 8 для України», «ULTRA Магазин» та «Бухгалтерія онлайн») та оцінивши ряд характеристик: ціна, простота інсталювання, використання, налаштування, функціонал, рівень підтримки; встановили, що спільним у всіх вище описаних програмних продуктах $\epsilon$ ïх висока вартість, вони $є$ комерційними, ціна за їхнє використання виправдана зручним інтерфейсом та широким функціоналом [3, 5, 6].

Варто відзначити, що в «1С: Роздріб 8 для України» та «ULTRA Магазин» основні звіти, інтеграція з 1C, робота 3 клієнтами, рівні доступу працівників дуже схожі візуально й функціонально.

Обидві програми треба встановлювати на комп'ютер; вони містять широкі можливості аналізу та аналітики, багаті можливості управління знижками, передбачені функції оформлення продажів продавця. Щодо системи Бухгалтерія онлайн: відрізняється від двох інших тим, що основна iï мета - це бухгалтерський облік, податковий облік і звітність. В ній немає продажу, чеків, товарів, проте - це цікава сучасна система, яка містить потужну базу для створення, редагування, перегляду звітів, їх аналізу, порівняння тощо $[2 ; 4 ; 6]$.

Отже, в сучасному світі багато систем для обліку магазину. Але порівнявши функціонал уже існуючих програм, проблема створення нової, кращої, якіснішої системи, без зайвих затрат пам'яті, призначеної для роботи у відносно невеликому підприємстві, але $з$ можливістю масштабувати, набуває все більшої актуальності.

Мета статті - показати етапи проектування автоматизованої системи обліку «АХIM» (АКСIM).

Виклад основного матеріалу дослідження.

Технічне завдання.

Назва програмного продукту автоматизована система обліку «АХIM» (AKCIM).

Автоматизована система обліку «АХIM» (АКСІМ) є синтезом серверної та клієнтської частини, що утворюють повноцінну систему для обліку та контролю магазином.

Місцем зберігання основних персональних даних $\epsilon$ шифрована захищена база даних «АХІМ» (БД «АХІМ»), створена за допомогою СУБД MySQL. В БД «AXIM» заносяться списки товарів, чеків, акцій, замовлень, накладних, користувачів, клієнтів, постачальників, доходів та каси. 
Система розроблена для роботи двох типів користувачів: «власник» та «продавець» 3 різними правами доступу та різним функціоналом.

Основним призначенням програмного продукту повинно бути ведення роздрібного продажу товарів (фіксація чеків, замовлень та повернень клієнтів і т.д.).

Веб-інтерфейс АСО «АХІМ» програмно реалізовано 3 використанням мов програмування: HTML, CSS, PHP та JavaScript.

Проектування бази даних.

Розглянемо

проектування концептуальної (рис. 1), логічної (рис. 2) та фізичної моделі бази даних «АХІМ». В концептуальній моделі бази даних «АХIM» описана предметна область системи в термінах мови MySQL.

Етап фізичного проектування полягає в тому, щоб дані, представлені на етапі логічного проектування інтерпретувати в систему управління базами даних (в нашому випадку - MySQL) відповідно синтаксису. Для цього створюємо файл з розширенням sql та за допомогою команд MySQL CREATE та INSERT формуємо структурно базу даних та заповнюємо всі таблиці мінімум по одному рядку.

Приклад створення (create) таблиці «users» та заповнення іii (insert):

create table users (login_user varchar(20) primary key, rights varchar(10), name_user varchar(50), status varchar(10));

insert into users values ('ivan', 'seller', 'Швець Іван Володимирович', 'активний').

Створення прочедур в базі даних.

Практичну реалізацію збереженої процедури розглянемо на прикладі видалення акцій та оновлення відповідної інформації. Для цього будуть задіяні наступні таблиці бази даних: «Products», «Shares» та «Product shares».

Необхідно створити таку процедуру, яка змогла б в день закінчення акції видаляти їі. Тобто в таблиці «Products» змінювати поле «price_share» та «active_share» на 0 (товар не $\epsilon$ в акціï); $з$ таблиці «Shares» видаляти акцію зі всіма іiі полями та 3 таблиці «Product_shares» видаляти всі товари відповідної акції, яка містить унікальний номер.

Рішення: створити збережену процедуру та подію, яка буде викликати цю процедуру кожен день в один і той самий час.

Алгоритм роботи процедури:

1. Видобування поточної дати:

select @cur_date:=CURDATE();
2. Добування ідентифікатора акції та дати її закінчення:

select

@id_share:=id_share, @ date_end_share:=date_end_share from shares where date_end_share $=@$ cur_date;

3. Порівняння сьогоднішньої дати та дати закінчення акції:

if (@date_end_share=@cur_date)...

4. Якщо сьогоднішня дата та дата закінчення акції співпадають, то по бар-коду відбувається оновлення таблиці «Products» полів «price_share» та «active_share»:

update products set price_share $=0$, active_share $=0 \quad$ WHERE bar_code=@bar_code;

5. Видалення продуктів акції з таблиці «product_shares»:

delete from product_shares WHERE bar_code=@bar_code;

6. Видалення власне акції 3 таблиці «shares» по ідентифікатору:

delete from shares WHERE id_share=@id_share;

Створивши процедуру, викликаємо іiі в події, кожного дня в 00:00:01:

CREATE EVENT drop_shares_event

ON SCHEDULE EVERY 1 DAY

STARTS '2019-03-15 00:00:01'

DO call drop_shares();

Функиія продажу для взаємодії користувачів з системою.

Розглянемо функцію Selling, за допомогою якої організована операція продажу. Припустимо, що товари та їх кількості уже обрано, залишилося лише підтвердити операцію, відповідно внести деякі зміни в БД. Коли відбувається продаж товару, формуємо масив 3 штрих кодів (bar code) та кількості (count) товарів. Натисненням на кнопку «Друк чеку» формується двовимірний масив та заповнюється даними в циклі «поки не закінчаться всі продукти».

Маючи масив даних про товари, їх кількості, ціни, поточну дату, дані продавця, передаємо їх в клас для роботи 3 БД DBAdapter у функцію Selling(). Результат виконання передаємо у функцію SuccesAddCountProd() класу View. Функція Selling() робить наступне:

1. Зменшує кількість товарів.

2. Додає новий чек в БД.

3. Додає товари в створений чек.

4. Додає загальну суму продажу та суму прибутку. 


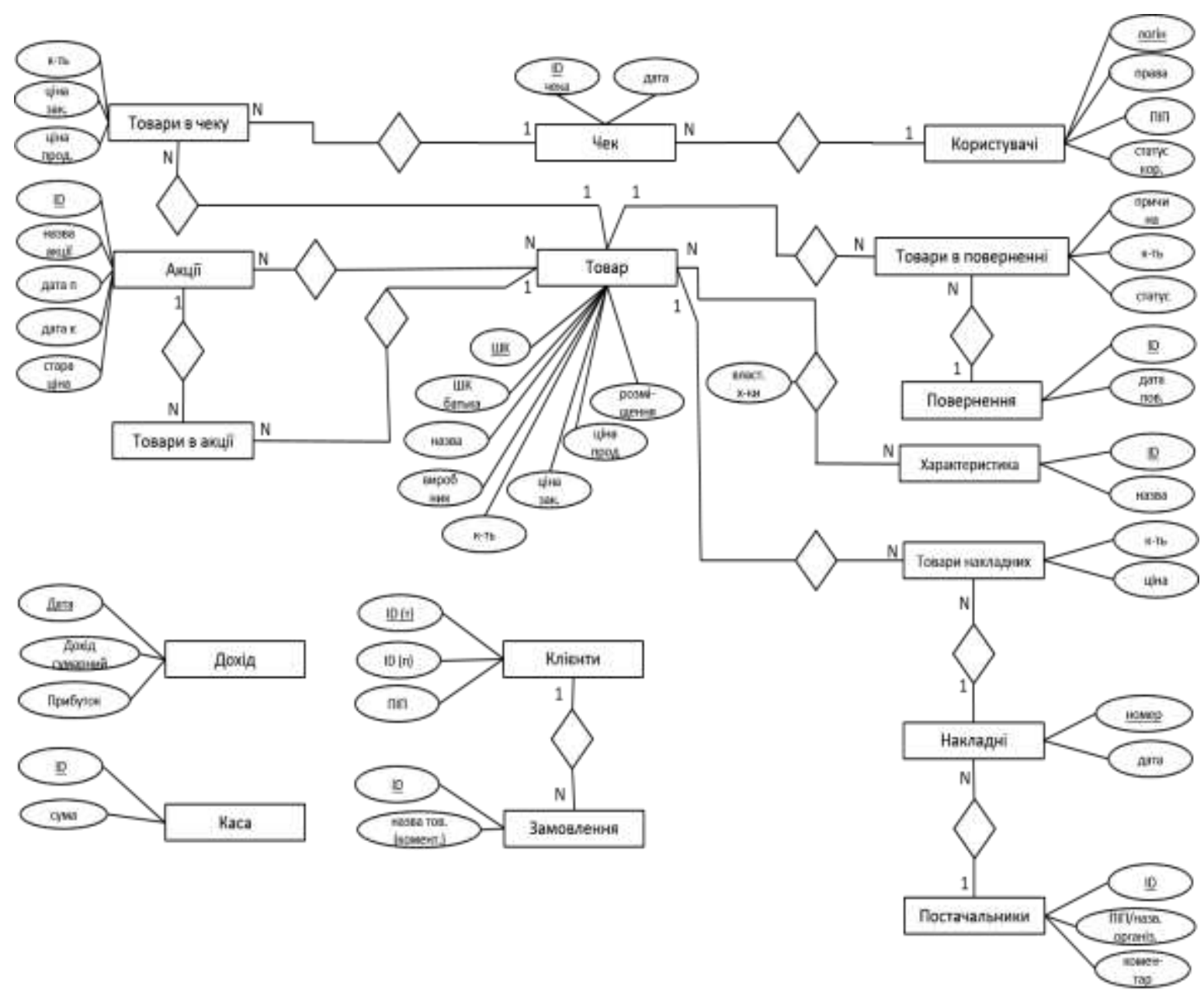

Рисунок 1. Концептуальна модель БД «АХІМ»

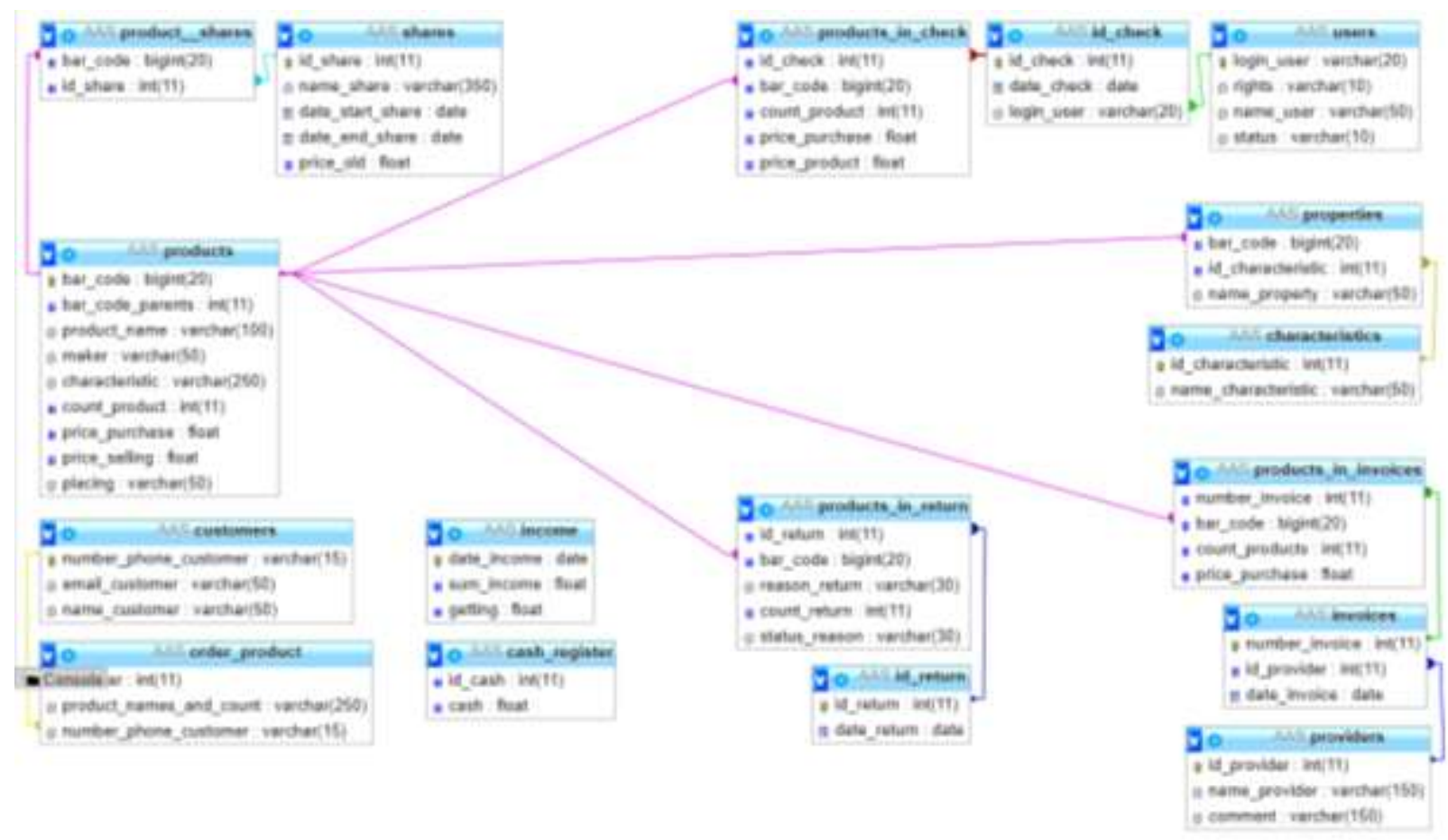

Рисунок 2. Логічна модель БД «АХІМ» 
Висновки та перспективи подальших розвідок напряму. Останнім часом, прагнення електронізувати щоденні процеси приходить у всі сфери людського життя: побут, освіта, бізнес. Як відомо, автоматизація будь-якого процесу не тільки спрощує роботу людини, а й зменшує час на iii виконання та покращує, власне, якість та ефективність цієї операції.

На сьогоднішній день все частіше механічну, монотонну роботу людей виконує автоматична чи автоматизована система. Це виправдано тим, що комп'ютерні програмні продукти виконують операції набагато швидше і якісніше, ніж людина.

$\mathrm{У}$ процесі розробки системи «АХIM» було виконано наступне: досліджено сучасні програмні продукти для обліку магазину та предметну область «Облік магазину роздрібної торгівлі»; розглянуто сучасні тенденції та стандарти у веб-дизайні; спроектовано базу даних для програмного продукту «АХIM» та розроблено модуль для роботи 3 базою даних; створено збережені процедури в MySQL для автоматизації процесів обліку; автоматизовано процеси заповнення даних користувачами та, власне, розроблено програмний продукт
автоматизована система обліку «АХІМ».

Отриманий програмний продукт має необхідний функціонал, практичну цінність та успішно виконує поставлені перед ним задачі.

\section{СПИСОК ДЖЕРЕЛ}

1. Автоматизація магазину - Intellect Technologies LLC [Електронний ресурс]. - Режим доступу до ресурсу: https://www.intellect.co.ua/avtomatizatsiya-magazinu.

2. Автоматизовані програми для магазинів та бутиків $\rightarrow$ Блог про ERP i CRM системах автоматизації бізнесу [Електронний ресурс]. Режим доступу до ресурсу: https://ultracompany.com/ua/dlya-chego-nuzhny-

avtomatizirovannye-programmy-dlya-magazinov-idrugih-torgovyh-zavedenij.

3. «БУХГАЛТЕРИЯ онлайн» для Вашей компании [Електронний ресурс]. - Режим доступу до pecypcy:

https://privatbank.ua/ru/business/bukhgaletriya-

onlajn-dl-a-vashej-kompanii.

4. Електронний документообіг [Електронний pecypc]. - Режим доступу: https://privatbank.ua/business/nds.

5. Програми автоматизації бізнесу Ultra завантажити демо версії програмного забезпечення бізнесу безкоштовно [Електронний pecypc]. - Режим доступу до ресурсу: https://ultracompany.com/ua.
6. Программные продукты 1С: Предприятие 8 [Електронний ресурс]. - Режим доступу до pecypcy: http://www.1c.kiev.ua/products/1s-roznitsa8-dlya-ukrainy.

\section{REFERENCES}

1. Avtomatyzatsiya mahazynu - Intellect Technologies LLC [WWW document]. - URL: https://www.intellect.co.ua/avtomatizatsiya-magazinu. $-(15.09 .2019)$

2. Avtomatyzovani prohramy dlya mahazyniv ta butykiv $\rightarrow$ Bloh pro ERP i CRM systemakh avtomatyzatsiyi biznesu [WWW document]. - URL: https://ultra-company.com/ua/dlya-chego-nuzhnyavtomatizirovannye-programmy-dlya-magazinov-idrugih-torgovyh-zavedenij. - (15.09.2019).

3. «BUKHHALTERYYA onlayn» dlya Vashey kompanyy [WWW document- URL: https://privatbank.ua/ru/business/bukhgaletriyaonlajn-dl-a-vashej-kompanii. - (15.09.2019).

4. Elektronnyy dokumentoobih [WWW document]. $\quad-\quad$ URL: https://privatbank.ua/business/nds. - (15.09.2019).

5. Prohramy avtomatyzatsiyi biznesu Ultra zavantazhyty demo versiyi prohramnoho zabezpechennya biznesu bezkoshtovno [WWW document]. - URL: https://ultra-company.com/ua. (15.09.2019).

6. Prohrammnye produkty 1S: Predpryyatye 8 [WWW document] URL: http://www.1c.kiev.ua/products/1s-roznitsa-8-dlyaukrainy. - (15.09.2019).

\section{ВІДОМОСТІ ПРО АВТОРІВ}

БОЛІЛИЙ Василь Олександрович кандидат фізико-математичних наук, доцент кафедри інформатики та IT Центральноукраїнського державного педагогічного університету імені Володимира Винниченка.

Наукові інтереси: диференціальні рівняння, задачі з точками звороту; проблеми модернізації навчального процесу; ІКТ у освіті; технології дистанційного навчання.

\section{INFORMATION ABOUT THE AUTHORS}

BOLILYJ Vasyl Oleksandrovych - Candidate of Sciences (Physics and Mathematics), Associate Professor of the Department of Informatics and Information Technologies of the Volodymyr Vynnychenko Centralukrainian State Pedagogical University.

Circle of research interests: differential equations; problems with turning points; problems of teaching process modernization; ICT in education; distance learning technology.

Стаття надійшла до редакиії 21.11.2019 p. 